\title{
Health Financing in Sub-Saharan Africa: From Analytical Frameworks to Empirical Evaluation
}

\author{
Augustine Asante $^{1}\left[\right.$ ( ) Wilson S. K. Wasike ${ }^{2}$ John E. Ataguba ${ }^{3}(\mathbb{C}$
}

Accepted: 19 October 2020 / Published online: 4 November 2020

(c) The Author(s) 2020

\section{Introduction}

Health financing is central to the functioning of health systems and the attainment of health-related sustainable development goals, including universal health coverage (UHC). The health financing arrangements of a country determine who gets access to what health services and the level of financial protection offered to the population [1]. Often the financing arrangements are influenced by the historical, social, political and economic development of the country $[2,3]$. In general, health financing covers three basic functions of revenue collection, risk pooling and purchasing of health services $[4,5]$. Revenue collection deals with raising of funds from different sources (taxes, social security/insurance systems, fees, grants, loans, etc.) to finance the health system [4]. Risk pooling involves combining and managing revenue in such a way that individuals in a pool share collective health risk and, in so doing, protect members of the pool from payment of applicable health expenditures. Purchasing is the transfer of pooled funds to health service providers to provide health services to the population $[4,6]$. Regardless of income level, all countries face challenges in financing healthcare. However, these challenges are more acute in lowand middle-income countries (LMICs), where the need for healthcare is greatest and resources are most scarce [7].

Global health spending has grown significantly in the last few decades, with total spending rising from \$US3.5 trillion

Augustine Asante

a.asante@unsw.edu.au

1 School of Population Health, University of New South Wales (UNSW) Sydney, Room 238, Level 2 Samuels Building, Sydney, NSW 2052, Australia

2 African Economic Research Consortium (AERC), Nairobi, Kenya

3 Health Economics Unit, School of Public Health and Family Medicine, Health Sciences Faculty, University of Cape Town, Cape Town, South Africa in 1995 to \$US8.0 trillion in 2016 [8]. This represents about $4 \%$ annual growth over the past two decades. Significant disparities exist, with per capita health spending in LMICs lagging far behind that of high-income countries (HICs). For example, health spending per capita in low-income countries (LICs) averaged about \$US110 in 2015 compared with \$US5551 in HICs [8]. The disparities between countries are more profound for government health spending than for other spending sources. On average, less than $30 \%$ of total health expenditure in LICs comes from government sources compared with nearly $80 \%$ in HICs [9]. Government health spending in countries such as Myanmar, Nepal and Haiti accounted for less than $20 \%$ of total health expenditure in 2015 [8]. As a consequence of low government health spending, many LMICs rely heavily on out-of-pocket (OOP) payments, which prevent millions of people from accessing health services and push millions into poverty [10].

Besides the need to increase the resource envelope for health services, efficient allocation and use of available resources are paramount to expanding access to quality health services. However, many LMICs are unable to allocate and/or use resources efficiently to maximise health gains $[7,11]$. One key source of inefficiency is the significant proportion of health budget allocated to hospital services at the expense of primary healthcare, which is fundamental to improving population health outcomes [12]. This skewed allocation of resources in favour of hospitals exacerbates inequalities in health as hospitals in LMICs are traditionally urban based and serve the more affluent segments of the population more than the poorer ones [12].

\section{Health Financing in Sub-Saharan Africa}

The need for a robust health financing system is crucial in sub-Saharan Africa (SSA), a region that accounts for a disproportionate share of the global disease burden [13] but allocates the least amount of resources to healthcare [10]. 
Health spending per capita in Africa averaged \$US80 in 2016 compared with \$US4003 in Organisation for Economic Co-operation and Development countries [8, 14]. Generally, health financing systems in SSA are characterised by low government spending, under-developed insurance schemes, high OOP payments, and high dependence on external (donor) funding $[15,16]$.

Domestic government health spending as a proportion of gross domestic product in the World Health Organization Africa region averaged $1.9 \%$ in 2017 compared with the global average of $3.3 \%$ [17]. In recognition of the centrality of healthcare to economic development, African governments in 2001 committed to the target set in the Abuja Declaration to devote at least $15 \%$ of their annual national budget to the health sector [18]. Nearly 20 years on, only a few countries in the region have reached this target. Average government health spending as a proportion of general government spending hovers around $7.2 \%$, less than half of the target set in Abuja [19]. With low government spending, OOP payments by households have become a prominent source of finance for health systems in the region. In countries such as Cameroon, Equatorial Guinea, Nigeria and Sudan, OOP health spending exceeded $70 \%$ of current health expenditure (CHE) in 2017 [20]. In general, OOP health spending averages around $36 \%$ of CHE in SSA, the second highest in the world behind South Asia [21]. Donor funding has traditionally played a key role in health financing in SSA, but its influence is waning. Donor funding presently accounts for less than $20 \%$ of CHE in many SSA countries [8]. However, few countries in the region still rely heavily on donor funding to finance their health sector. In Malawi and Mozambique, for example, donor funding accounts for more than $60 \%$ of CHE [8]. The bulk of donor funding is allocated to specific health programmes in the fields of HIV/ AIDS, malaria, tuberculosis, and-more recently-maternal and child health [22].

\section{Content of this Special Issue}

In recognition of the numerous health financing challenges facing countries in SSA, the African Economic Research Consortium (AERC) commissioned research to provide rigorous evaluative frameworks to assess different aspects of health financing on the continent. This special issue contains eight papers that emerged from the AERC research, covering different issues. These papers examine health financing in SSA from three different perspectives. The first three papers [23-25] propose frameworks for analysing health financing equity and sustainability. Ataguba et al. [23] advance a framework for assessing the impact of health financing on changes in income inequalities (i.e. the redistributive effect) between and within population groups. This framework extends the current approaches to decomposing the redistributive effect of health financing by shifting the emphasis from income inequalities in the entire population to inequalities between and within population groups. They use data from Nigeria to illustrate how the framework can be applied. They report that OOP payments for health services that contribute to increasing income inequalities, especially within the geopolitical zones in Nigeria, should be minimised.

Asante et al. [24] focus on the evaluation of health financing equity using benefit incidence analysis (BIA) and propose a framework for accounting for quality of care, an aspect yet to be explored in the literature. They argue that the current BIA approach fails to account for variations in the quality of health services and could potentially lead to under/ over-estimation of healthcare benefits (the amount of public subsidy captured by individuals through their use of health services) received by different socioeconomic groups. They use data from Cambodia to illustrate how quality scores may be generated and used to conduct BIA that accounts for the quality of healthcare. They note that incorporating quality scores into BIA assessment substantially affects the amount of benefit obtained by different socioeconomic groups. The last framework paper deals with analysing the financial sustainability of user fee removal policies. Mathonnat et al. [25] present a methodological framework for a rapid first assessment of the financial sustainability of user fee removal policies. Although the authors use data from Burkina Faso to demonstrate the applicability of the framework under different scenarios, they note its universal applicability.

The next batch of papers (three in total) undertakes empirical analyses of specific health financing issues in SSA. Ssewanyana and Kasirye [26] estimate catastrophic health expenditures from household surveys in five countries: Ethiopia, Malawi, Nigeria, Tanzania and Uganda. They note that the burden of catastrophic health expenditures remains substantial in SSA and call for renewed attention to the expansion of public revenues to finance health expenditures. Atim et al. [27] analyse domestic financing for reproductive, maternal, neonatal and child health (RMNCH), highlighting the potential gains from increased domestic financing and the fiscal space available for financing RMNCH in SSA. Their results point to strong gains from domestic public health financing for RMNCH. They also find potential fiscal space for RMNCH from improving public financial management, particularly the efficiency and effectiveness of tax collection. Jacobs et al. [28] explore the role of performancebased financing (PBF) within health financing policies with specific reference to user fees or exemption policies, basic packages of health services and benefit packages in three fragile and conflict-affected settings-Central African Republic, the South Kivu province in eastern Democratic Republic of Congo, and Adamawa State in northern Nigeria. They report that, where national leadership is stronger, PBF 
is better integrated and more in line with the health financing regulations and can provide structure and organisation to the system in times of acute crisis.

The final two papers review the health financing literature to highlight critical issues relating to strategic purchasing and health insurance coverage. Honda and Obse [29] examine private healthcare purchasing under publicly financed health systems in LMICs. They argue that the payment methods and rates applied to private and public health providers need careful attention to ensure equity, efficiency and quality in healthcare provision. They highlight inter alia the need for transparent mechanisms to establish payment rates and for a sound legal framework to ensure that payment arrangements assist public purchasers to strategically purchase private healthcare under the public system. Degroote et al. [30] conduct a scoping review of the methods used to evaluate the impact of health insurance. They observe that the evidence for the impact of health insurance in SSA is derived primarily from observational studies that cannot discern causal relationships but only highlight an association between the outcome of interest and insurance exposure. They note, however, that the number of experimental and quasi-experimental studies is increasing, and this could substantially expand and improve the evidence base on the impacts of health insurance on the continent.

\section{Concluding Remarks}

Together, these papers highlight the diverse health financing challenges confronting SSA countries and the opportunities to address some of them using new methodological frameworks. High OOP payments, low government health spending, and lack of policy clarity around purchasing of healthcare from private providers by public purchasers are among the challenges identified in the papers in this special issue. The persistently high OOP expenditures in SSA raise concerns about the prospect of achieving the goal of UHC in the region, especially given that it is primarily the poor who make these catastrophic payments [26]. It highlights the extent of financial protection across the continent and the need to do more to protect the most vulnerable. Closely related to the high OOP payments is the issue of low government health spending. Most of the papers in this issue note the need to expand public expenditure on healthcare in SSA. This is becoming more critical as donor funding for health is set to fall considering the slowdown in the global economy fuelled by the COVID-19 pandemic [31], among other things. Finally, countries in SSA that have introduced health insurance to make healthcare more accessible to their populations face several design challenges. Some of these insurance systems lack a sound legal framework that ensures payment arrangements assist public purchasers to strategically purchase services from private providers [29]. With budgets stretched in many countries in SSA, such a legal framework will ensure that appropriate laws are enacted to hold actors in the insurance sector accountable. This will reduce financial malpractice and help maximise available resources. Opportunities exist to tackle some of the challenges highlighted in the papers contained in this special issue, especially those related to equity and sustainability of health financing in SSA. The frameworks proposed in the first three papers [23-25], for instance, will provide an avenue to scrutinise health financing systems in Africa, and we look forward to future empirical applications of these frameworks as we move towards ensuring UHC in SSA.

Acknowledgements This special issue was supported by the African Economic Research Consortium (AERC). The views expressed herein are those of the authors and not necessarily those of the AERC.

\section{Declarations}

Conflict of interest Augustine Asante, Wilson S. K. Wasike, and John E. Ataguba have no conflicts of interest that are directly relevant to the content of this manuscript.

Open Access This article is licensed under a Creative Commons Attribution-NonCommercial 4.0 International License, which permits any non-commercial use, sharing, adaptation, distribution and reproduction in any medium or format, as long as you give appropriate credit to the original author(s) and the source, provide a link to the Creative Commons licence, and indicate if changes were made. The images or other third party material in this article are included in the article's Creative Commons licence, unless indicated otherwise in a credit line to the material. If material is not included in the article's Creative Commons licence and your intended use is not permitted by statutory regulation or exceeds the permitted use, you will need to obtain permission directly from the copyright holder. To view a copy of this licence, visit http://creativecommons.org/licenses/by-nc/4.0/.

\section{References}

1. Tangcharoensathien V, Patcharanarumol W, Ir P, et al. Healthfinancing reforms in southeast Asia: challenges in achieving universal coverage. Lancet. 2011;377:863-73.

2. Asante AD, Jacobs B, Wiseman V. Transforming health systems financing in Lower Mekong: making sure the poor are not left behind. Health Policy Plan. 2019;34:i1-3.

3. Ichoku HE, Fonta WM, Ataguba JE. Political economy and history: making sense of health financing in sub-Saharan Africa. J Int Dev. 2012;25:297-309.

4. Schieber G, Baeza C, Kress D, Maier M, et al. Financing health systems in the 21 st century. In: Jamison DT, Breman JG, Measham AR, et al., editors. Disease control priorities in developing countries. New York: The World Bank and Oxford University Press; 2006.

5. Kutzin J. A descriptive framework for country-level analysis of health care financing arrangements. Health Policy. 2001;56:171-204. 
6. McIntyre D. Learning from experience: health care financing in low-and middle-income countries. Geneva: Global Forum for Health Research; 2007.

7. World Health Organization. The world health report 2010: health systems financing - the path to universal coverage. Geneva: World Health Organization; 2010.

8. Chang AY, Cowling K, Micah AE, et al. Past, present, and future of global health financing: a review of development assistance, government, out-of-pocket, and other private spending on health for 195 countries, 1995-2050. Lancet. 2019;393(10187):2233-60.

9. World Health Organization. Public spending on health: a closer look at global trends. Geneva: World Health Organization; 2018a.

10. Wagstaff A, Flores G, Smitz M-F, et al. Progress on impoverishing health spending in 122 countries: a retrospective observational study. Lancet Glob Health. 2018;6:e180-92.

11. Babalola TK, Moodley I. Assessing the efficiency of health-care facilities in sub-Saharan Africa: a systematic review. Health Serv Res Manag Epidemiol. 2020;7:2333392820919604.

12. Goodyear-Smith F, Bazemore A, Coffman M, et al. Primary care financing: a systematic assessment of research priorities in lowand middle-income countries. BMJ Glob Health. 2019;4:e01483.

13. Gouda HN, Charlson F, Sorsdahl K, et al. Burden of non-communicable diseases in sub-Saharan Africa, 1990-2017: results from the Global Burden of Disease Study 2017. Lancet Glob Health. 2019;7:e1375-87.

14. OECD. Health at a glance 2017. OECD indicators. Paris: OECD Publishing; 2017. https://doi.org/10.1787/health_glance-2017-en.

15. World Health Organization. State of health financing in the African region. Geneva: World Health Organization; 2013. https:// www.afro.who.int/publications/state-health-financing-africanregion.

16. Mcintyre D, Obse A, Barasa E, Ataguba JE. Challenges in financing universal health coverage in sub-Saharan Africa. Oxf Rese Encycl Econ Financ. 2018. https://doi.org/10.1093/acrefore/97801 90625979.013.2817.

17. Xu K, Soucat A, Kutzin, et al. Global spending on health: a world in transition. Geneva: World Health Organization; 2019. https:// www.who.int/health_financing/documents/health-expenditur e-report-2019/en/.

18. World Health Organization. The Abuja Declaration: ten years on. Geneva: World Health Organization; 2011. https://www.who.int/ healthsystems/publications/abuja_declaration/en/.

19. World Health Organization. World health statistics 2020: monitoring health for the SDGs sustainable development goals. Geneva: World Health Organization; 2020.

20. World Health Organization. Global health expenditure database: NHA indicators. https://apps.who.int/nha/database/ViewData/ Indicators/en.

21. World Health Organization. World health statistics 2018. Geneva: World Health Organization; 2018b.
22. Micah AE, Chen CS, Zlavog BS, et al. Trends and drivers of government health spending in sub-Saharan Africa, 1995-2015. BMJ Glob Health. 2019;4:e001159.

23. Ataguba JE, Ichoku HE, Nwosu CO, Akazili J. An alternative approach to decomposing the redistributive effect of health financing between and within groups using the Gini Index: the case of out-of-pocket payments in Nigeria. J Appl Health Econ Health Policy. 2019. https://doi.org/10.1007/s40258-019-00520-4 (Epub 18 Oct 2019).

24. Asante A, Man N, Wiseman V. Evaluating equity in health financing using benefit incidence analysis: a framework for accounting for quality of care. J Appl Health Econ Health Policy. 2020. https ://doi.org/10.1007/s40258-020-00597-2 (Epub 22 Jun 2020).

25. Mathonnat J, Audibert M, Belem S. Analyzing the financial sustainability of user fee removal policies: a rapid first assessment methodology with a practical application for Burkina Faso. Appl Health Econ Health Policy. 2019. https://doi.org/10.1007/s4025 8-019-00506-2 (Epub 21 Aug 2019).

26. Ssewanyana S, Kasirye I. Estimating catastrophic health expenditures from household surveys: evidence from Living Standard Measurement Surveys (LSMS)-Integrated Surveys on Agriculture (ISA) from Sub-Saharan Africa. Appl Health Econ Health Policy. 2020. https://doi.org/10.1007/s40258-020-00609-1 (Epub 10 Sep 2020).

27. Atim C, Arthur E, Achala DM, Novignon J. An assessment of domestic financing for reproductive, maternal, neonatal and child health in sub-Saharan Africa: potential gains and fiscal space. Appl Health Econ Health Policy. 2019. https://doi.org/10.1007/ s40258-019-00508-0 (Epub 12 Sep 2019).

28. Jacobs E, Bertone MP, Toonen J, Akwataghibe N, Witter S. Performance-based financing, basic packages of health services and user-fee exemption mechanisms: an analysis of health-financing policy integration in three fragile and conflict-affected settings. Appl Health Econ Health Policy. 2020. https://doi.org/10.1007/ s40258-020-00567-8 (Epub 20 Mar 2020).

29. Honda A, Obse A. Payment arrangements for private healthcare purchasing under publicly funded systems in low-and middleincome countries: issues and implications. Appl Health Econ Health Policy. 2020. https://doi.org/10.1007/s40258-019-00550 -y (Epub 22 Jan 2020).

30. Degroote S, Ridde V, De Allegri MJ. Health insurance in subSaharan Africa: a scoping review of the methods used to evaluate its impact. Appl Health Econ Health Policy. 2019. https://doi. org/10.1007/s40258-019-00499-y (Epub 30 Jul 2019).

31. Ataguba JE. COVID-19 pandemic, a war to be won: understanding its economic implications for Africa. Appl Health Econ Health Policy. 2020;18(3):325-8. 